\title{
Short- and medium-term survival of critically ill patients with solid cancer admitted to the intensive care unit
}

\author{
Zhen-Nan Yuan, Hai-Jun Wang, Yong Gao, Shi-Ning Qu, Chu-Lin Huang, Hao Wang, Hao Zhang, \\ Xue-Zhong Xing
}

Department of Intensive Care Unit, National Cancer Center/National Clinical Research Center for Cancer/Cancer Hospital, Chinese Academy of Medical Sciences \& Peking Union Medical College, Beijing, China

Contributions: (I) Conception and design: XZ Xing, ZN Yuan; (II) Administrative support: XZ Xing; (III) Provision of study materials or patients: SN Qu, CL Huang, H Wang; (IV) Collection and assembly of data: H Zhang, ZN Yuan; (V) Data analysis and interpretation: Y Gao, ZN Yuan; (VI) Manuscript writing: All authors; (VII) Final approval of manuscript: All authors.

Correspondence to: Xue-Zhong Xing, PhD. Department of Intensive Care Unit, National Cancer Center/National Clinical Research Center for Cancer/Cancer Hospital, Chinese Academy of Medical Sciences \& Peking Union Medical College, Beijing 100021, China. Email: xxzncc@163.com.

Background A great increase in the number of patients needs critical care to the intensive care unit (ICU) due to improvements in oncology. The aim of the study was to explore risk factors affecting survival of critically ill patients with solid cancers in ICU.

Methods: The study retrospectively reviewed patients between 2001 and 2012, which were collected by Medical Information Mart for Intensive Care III (MIMIC-III) from the Beth Israel Deaconess Medical Center in Boston, MA, USA.

Results: A total of 38,508 adult patients, who were admitted to ICUs and 8,308 (21.6\%) were diagnosed as an underlying malignancy; 1,671 and 3,165 adult patients with sold cancer were admitted to surgical ICU (SICU) and medical ICU (MICU), respectively. Patients in SICU had a higher survival rate at the point of 28-, 90-day, and 1-, 3-year than patients in MICU ( $\mathrm{P}<0.001$ for all). Multivariate analysis demonstrated that age $\geq 70$, emergency admission, the presence of metastases, Oxford Acute Severity of Illness Score (OASIS) $\geq 30$ and sepsis were independent risk factors affecting 28-day survival in SICU. In MICU, emergency admission, metastatic disease, Sequential Organ Failure Assessment (SOFA) $\geq 3$, Simplified Acute Physiology Score II (SAPS II) $\geq 39$, Acute Physiology Score III (APS III) $\geq 40$, Oxford Acute Severity of Illness Score (OASIS) $\geq 30$, Elixhauser comorbidity index $\geq 9$ and sepsis were independent risk factors for 28-day survival rate. The area under curve (AUC) of the OASIS for predicting ICU mortality was 0.824 [95\% confidence interval (CI): 0.805-0.842], which was obviously higher than other scores in SICU. The AUC of the SAPS II for predicting ICU mortality was 0.820 (95\% CI: 0.806-0.833), which was slightly higher than other scores in MICU.

Conclusions: Patients with cancer in SICU have longer survival time than patients with cancer in MICU. The prediction of prognosis of critically ill cancer patients can guide treatment and optimize medical resources.

Keywords: Solid cancer; intensive care unit (ICU); critical illness; prognosis

Submitted Aug 22, 2021. Accepted for publication Dec 03, 2021.

doi: 10.21037/apm-21-2352

View this article at: https://dx.doi.org/10.21037/apm-21-2352 


\section{Introduction}

Historically, patients with cancer were rejected for admission to intensive care unit (ICU) because of shortterm survival $(1,2)$. Advances in oncology have led to a dramatic reduction in mortality rates in cancer patients over the past few decades $(3,4)$. As a result, the demand for critical care input to support cancer patients also increased due to therapies or the complications related to cancer $(5,6)$, These reasons included postoperative care after complicated surgeries, severe cancer or therapy related complications (bone marrow suppression and perforation), and exacerbation of chronic disease (7). It was reported that $5 \%$ of cancer patients need ICU admission because of critical illness within 2 years of malignancy diagnosis $(5,8)$. Cancer patients account for $15 \%$ of all admissions to ICU (9). Taccone et al. (10) conducted a multicenter, observational study including data from 198 participating ICUs from 24 European countries, in which about $12 \%$ of patients admitted to ICUs had a diagnosis of malignancy. Critical care can be provided but the burden of therapy can't be ignored and therefore it will only be carried out when there is a reasonable expectation of survival (11).

The aim of this study was to explore risk factors predicting prognosis of critically ill patients with solid cancers in ICU and decide the best time to provide critical care. We present the following article in accordance with the STROBE reporting checklist (available at https://apm. amegroups.com/article/view/10.21037/apm-21-2352/rc).

\section{Methods}

\section{Clinical database}

Medical Information Mart for Intensive Care III (MIMIC-III) is a large, freely-available database comprising more than 40,000 patients admitted to the of the Beth Israel Deaconess Medical Center between 2001 and 2012. It is also one of the very few databases with granular and continuous monitoring data of thousands of patients (12). After completing Collaborative Institutional Training Initiative (CITI) web-based training called "Data or Sample Research", we were granted permission to access the database (record ID: 36067767). This study used a public de-identification database, so there is no need to obtain the approval of the Institutional Review Board. The study was conducted in accordance with the Declaration of Helsinki (as revised in 2013).

\section{Data extraction}

Data extraction from MIMIC-III was via Structured Query Language (SQL) with PostgreSQL (version 9.6). The extracted data including gender, age, ethnicity, ICU type, main reasons for ICU admission, the severity of illness score, Elixhauser comorbidity index, mechanical ventilation (MV), vasopressor administration, renal replacement therapy (RRT), sepsis and hospital infection. For the parameters of the severity of the illness, only the data within the first 24 hours admitted to ICU were extracted. The reason for the patient's admission to the ICU was based on the highest score in the SOFA score on the first day of admission to the ICU. Mental disorder means that the Glasgow Coma Scale score is less than 9 points, and the cardiovascular disorder mainly refers to the Sequential Organ Failure Assessment (SOFA) score involving circulation items with a score of 4 points, which mainly represents patients with severe shock. The endpoints of our study were survival rates at 28-, 90-day, and 1-, 3-year after ICU admission. The information collected in the database is complete, and no patients are lost to follow-up. The information related patients' survival was extracted from Social Security Death Index records.

\section{Population selection criteria}

Selected cancer patients ( $\geq 18$ years) meet the Ninth Revison of International Classification of Diseases-9 (ICD-9) code. The infection (13) was also used the ICD-9 Clinical Modification codes. Patients were allowed to enter the study only when they were admitted to ICU firstly.

\section{The severity of illness score and comorbidity index}

The severity of illness score was assessed by the SOFA score (14), Simplified Acute Physiology Score II (SAPS II) (15), Logistic Organ Dysfunction Score (LODS) (16), Oxford Acute Severity of Illness Score (OASIS) (17) and Acute Physiology Score III (APS III) (18). The Elixhauser comorbidity index is used to assess comorbidities, which scores multiple comorbidities based on the severity of organ injure (19).

\section{Statistical analysis}

Categorical variables were expressed as the number and 
percentage, and Chi-square test was used to compare differences between groups. Continuous variables were described as median and quartiles, and were analyzed with non-parametric methods (Mann-Whitney-Wilcoxon for two groups, Kruskal-Wallis for multi-groups). The timedependent survival rate were calculated by Kaplan-Meier curves; the comparisons was assessed by the log-rank test. The cox proportional hazards model was used to determine the association between factors and 28-day survival in solid cancer patients admitted to surgical ICU (SICU) and medical ICU (MICU); these results are expressed as a hazard ratio (HR) with a $95 \%$ confidence interval (CI). The discriminative power is decided by comparing the area under the receiver operating characteristic (ROC) curve of each score separately. A $\mathrm{P}$ value $<0.05$ is considered statistically significant. Stata version 14.0 (Stata Corp, College Station, TX, USA) was used for statistical analysis.

\section{Results}

\section{Characteristics of the study population}

During the study period, there were 1,671 patients and 3,165 adult patients with solid cancer admitted to SICU and MICU, respectively. Table 1 gives solid cancer patients' admissions characteristics in SICU and MICU. Patients with solid cancer in SICU are younger than patients in MICU $(\mathrm{P}<0.001)$. Patients in SICU stay slightly longer than patients in MICU $(3.9 \pm 0.2$ vs. $3.5 \pm 0.1 ; \mathrm{P}=0.002)$. The gender was otherwise similar between these patients in SICU and MICU (P=0.189); 69.9\% of patients in SICU had been admitted to hospital as an emergency in contrast to $90.4 \%$ of the population in MICU. The percentage of patients with local tumor in SICU is slightly higher than that of in $\mathrm{MICU}(82.3 \%$ vs. $79.4 \%, \mathrm{P}=0.017)$. Cancer patients in MICU have higher critical illness score compared with patients in SICU. The Elixhauser comorbidity index of patients in MICU is obviously higher than that in SICU $\{13$ [6-21] vs. 9 [0-15]; $\mathrm{P}<0.001\}$. In SICU, fewer patients receive adjuvant therapy (including chemotherapy or immunosuppressive) compared patients in MICU. MV was the most common way of support for both groups at $41.5 \%$ (694 of 1,671 patients) in SICU and $29.4 \%$ (931 of 3,165 patients) in MICU. Cardiovascular support was provided to $16.6 \%$ of the SICU group (277 of 1,671 patients) and $19.7 \%$ of the MICU group (624 of 3,165 patients). It was not common to provide RRT in either group. Compared with patients in MICU, patients in SICU have a lower proportion of infection $(33.5 \%$ vs. $56.6 \% ; \mathrm{P}<0.001)$ and sepsis $(4.4 \%$ vs. $13.4 \% ; \mathrm{P}<0.001)$. Among patients included, 799 people died in the hospital. There were about 65 cases undergoing cardiopulmonary resuscitation in the database in total, including 5 patients in MICU and 60 patients in SICU.

\section{Frequency and survival of various types of solid cancer in SICU and MICU}

Patients in MICU had a lower survival rate at the time of 28-, 90-day, and 1-, 3-year after ICU admission $(\mathrm{P}<0.001$ for all) (Figure 1). Table 2 describes all solid cancer types admitted to ICU during the period along with 28-day survival. The short-term survival rates of different cancer types varied considerably. Metastatic cancer is the most common type of cancer admitted to ICU as a surgical admission and medical admission with 296 (17.71\%) patients and 651 (20.57\%) patients, respectively; 28-day survival rate was lowest for patients with bone and pancreas cancer patients in SICU. The lowest 28-day survival for types of malignancy in MICU were liver cancer (57.7\%), metastasis cancer $(59.1 \%)$, esophagus cancer $(59.2 \%)$, and lung cancer $(62.6 \%)$.

\section{Univariate and multivariate analysis of factors affecting 28-day survival among patients with solid cancer admitted by SICU and MICU}

In Table 3, multivariate analysis showed that age $\geq 70$, emergency admission, the presence of metastases, OASIS $\geq 30$ and sepsis were independent risk factors affecting 28-day survival in SICU. In MICU, emergency admission, metastatic disease, SOFA $\geq 3$, SAPS II $\geq 39$, APS III $\geq 40$, OASIS $\geq 30$, Elixhauser comorbidity index $\geq 9$ and sepsis were independent risk factors for 28-day survival.

\section{Discriminatory power of five severity of illness scores in predicting ICU survival in patients with solid cancer in SICU and MICU}

As shown in Table 4, five severity of illness scores have a good ability to predict the ICU mortality. The area under curve (AUC) of the OASIS for predicting ICU mortality was 0.824 (95\% CI: $0.805-0.842)$, which was significantly higher than other scores in SICU (Figure 2). The cut-off of OASIS was 33 with a specificity of $71.13 \%$, a sensitivity of $78.51 \%$. The predictive ability of the SOFA score is slightly 
Table 1 Patients' characteristics for admissions to ICU with solid cancer in SICU and MICU

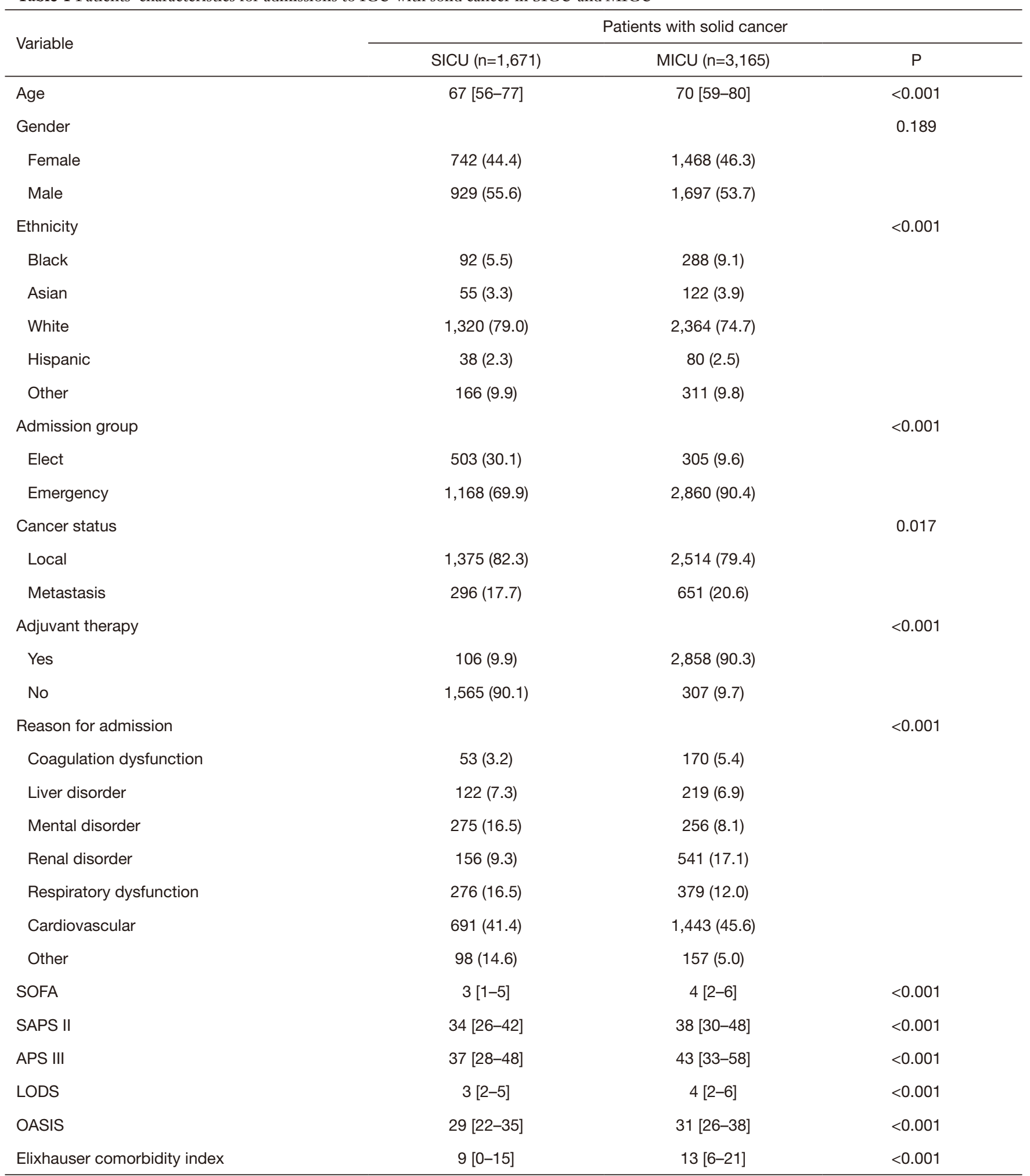

Table 1 (continued) 
Table 1 (continued)

\begin{tabular}{|c|c|c|c|}
\hline Variable & \multicolumn{3}{|c|}{ Patients with solid cancer } \\
\hline RRT & & & 0.359 \\
\hline Yes & $27(1.6)$ & $63(2.0)$ & \\
\hline No & $1,644(98.4)$ & $3,102(98.0)$ & \\
\hline Yes & $694(41.5)$ & $931(29.4)$ & \\
\hline No & 977 (58.6) & 2,234 (70.6) & \\
\hline Vasoactvie & & & 0.008 \\
\hline Yes & $277(16.6)$ & $624(19.7)$ & \\
\hline Yes & $73(4.4)$ & $423(13.4)$ & \\
\hline No & $1,598(95.6)$ & $2,742(86.7)$ & \\
\hline Infection & & & $<0.001$ \\
\hline Yes & $560(33.5)$ & $1,790(56.6)$ & \\
\hline No & $1,111(66.5)$ & $1,375(43.4)$ & \\
\hline Length of ICU stay (day) & $3.9 \pm 0.2$ & $3.5 \pm 0.1$ & 0.002 \\
\hline
\end{tabular}

ICU, intensive care unit; SICU, surgical intensive care unit; n, number; MICU, medical intensive care unit; P, probability; SOFA, Sequential Organ Failure Assessment; SAPS II, Simplified Acute Physiology Score II; APS III, Acute Physiology Score III; LODS, Logistic Organ Dysfunction Score; OASIS, Oxford Acute Severity of Illness Score; RRT, renal replacement therapy; MV, mechanical ventilation.

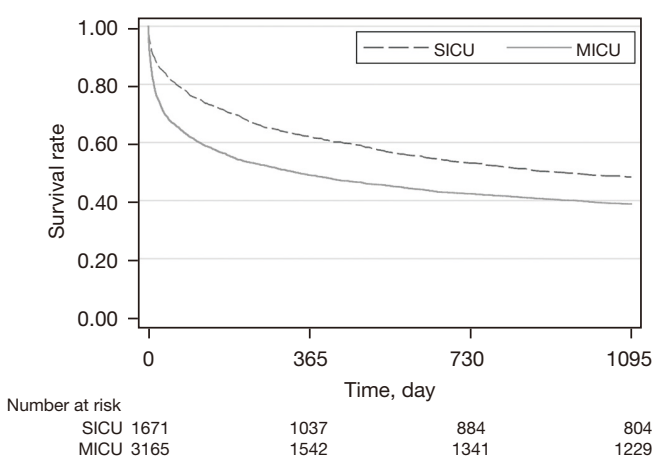

Figure 1 Patients in SICU had a higher survival rate at the point of 28-, 90-, 365- and 1,095-day after ICU admission ( $\mathrm{P}<0.001$ for all). SICU, surgical intensive care unit; MICU, medical intensive care unit; ICU, intensive care unit. weaker with the AUC of 0.685 (95\% CI: 0.663-0.708). Results of comparison of the five scores were similar when they were used to predict ICU mortality in MICU. The AUC of the SAPS II for predicting ICU mortality was 0.820 (95\% CI: 0.806-0.833), which was slightly higher than other scores in MICU (Figure 3). The cut-off of SAPS II was 46 with a specificity of $79.20 \%$, a sensitivity of $71.07 \%$.

\section{Discussion}

In the study, cancer patients in MICU have a higher incidence of organ dysfunction and require more intensive support (such as MV, vasopressors, and RRT), which was consistent with previous literature (20). Patients in SICU 
Table 2 Frequency and short survival of solid cancer types in SICU and MICU

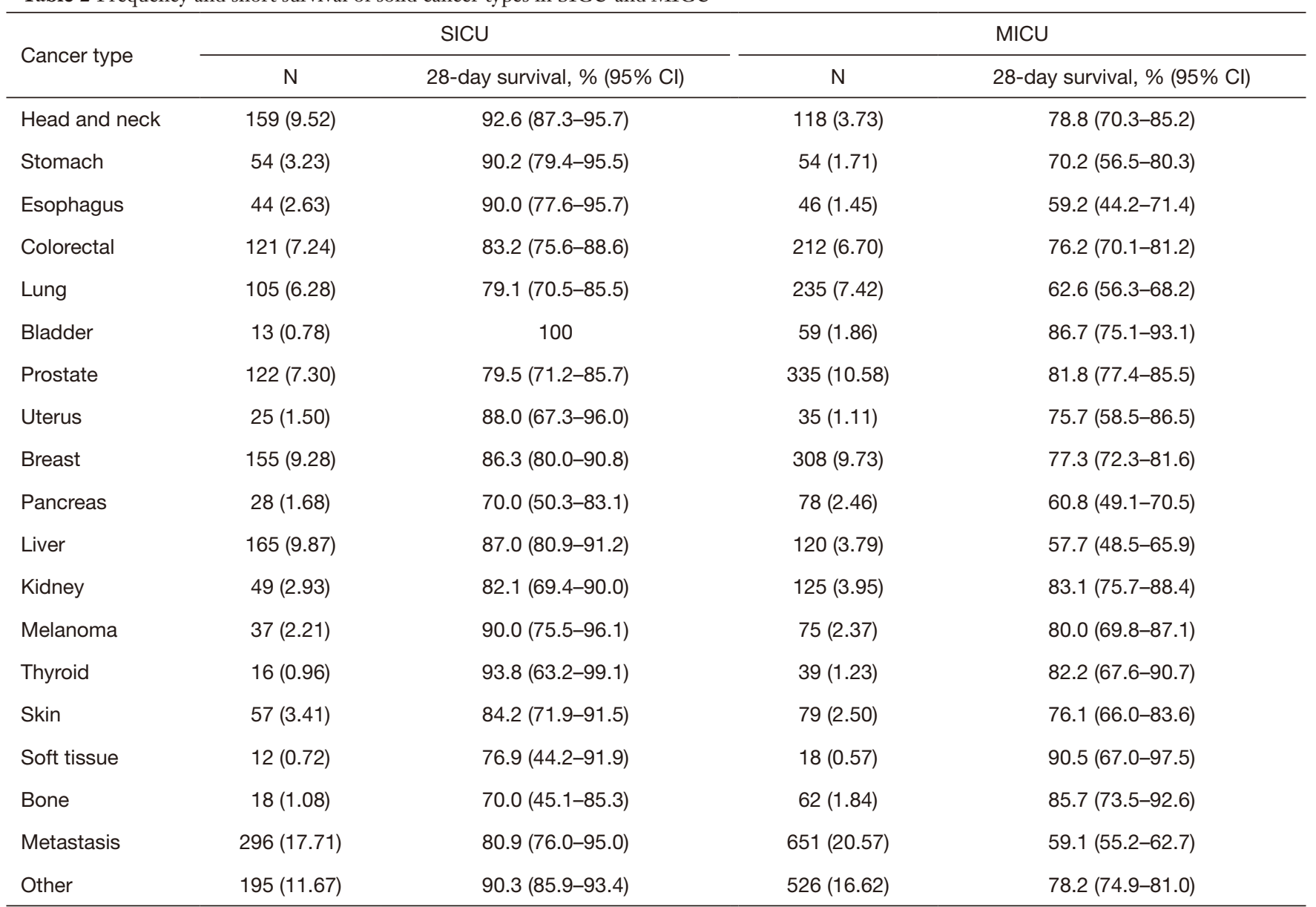

MICU, medical intensive care unit; SICU, surgical intensive care unit; N, number; $\mathrm{Cl}$ confidence interval.

have a survival advantage than patients in MICU. The prognosis of cancer patients by emergency admission is worse than that of elective admissions, and the prognosis of patients admitted by medical admission is worse than that of surgical admissions. Patients who are admitted to SICU are generally in good condition, and the lesions may have been completely removed during surgery. Therefore, the prognosis is better. A prospective, multicenter, cohort study of ICUs from 28 hospitals in Brazil conducted by Soares et al. (21), found that short-term survival was mostly dependent on the severity of organ injure (such as need for MV) rather than cancer-related factors, such as the type of cancer.

Recent advance in anti-cancer treatment has gradually improved the overall survival of patients with metastatic cancer $(22,23)$. Patients with metastatic cancer in SICU usually have resectable lesions, while those in MICU were multiply metastasis and they don't have chances for surgery. So metastatic patients have a significant survival advantage in SICU than those in MICU (80.9\% vs. $59.1 \%$ for 28 -day survival rate).

Patients with diagnosis of malignancy in MICU have a higher rate of infections or sepsis than those in SICU. Moreover, cancer related to treatment has led to more and more immunocompromised patients and an increase in the incidence of nosocomial infections; immunosuppression will also lead to more hospital infections (24). For cancer patients, one of the major causes of ICU admission is sepsis (6) and is an important factor affecting short-term survival (10). It has been reported that $17 \%$ of medical admissions related to sepsis have cancer (25). As expected, immunodeficiency was more common among the medical cancer patients. Among patients with solid tumors in SICU and MICU, sepsis is an independent risk factor affecting 
Table 3 Univariate and multivariate analysis of factors affecting 28-day survival among patients with solid cancer admitted by SICU and MICU

\begin{tabular}{|c|c|c|c|c|c|c|c|c|}
\hline \multirow{2}{*}{ Variable } & \multicolumn{4}{|c|}{ Patients with solid cancer admitted by SICU $(n=1,671)$} & \multicolumn{4}{|c|}{ Patients with solid cancer admitted by MICU $(n=3,165)$} \\
\hline & $\mathrm{N}$ & $\mathrm{P}$ & $\mathrm{HR}(95 \% \mathrm{Cl})$ & $\mathrm{P}$ & $\mathrm{N}$ & $\mathrm{P}$ & $\mathrm{HR}(95 \% \mathrm{Cl})$ & $\mathrm{P}$ \\
\hline \multicolumn{9}{|l|}{ Age } \\
\hline$<70$ & 965 & 0.001 & Reference & $<0.001$ & 1,580 & 0.108 & NA & NA \\
\hline \multicolumn{9}{|l|}{ Gender } \\
\hline Female & 742 & 0.654 & NA & NA & 1,468 & 0.666 & NA & NA \\
\hline Male & 929 & & NA & & 1,697 & & NA & \\
\hline \multicolumn{9}{|l|}{ Ethnicity } \\
\hline White & 1,320 & & $1.531(0.779-3.014)$ & 0.218 & 2,364 & & $0.917(0.728-1.158)$ & 0.469 \\
\hline Hispanic & 38 & & $1.531(0.505-4.644)$ & 0.452 & 80 & & $0.642(0.350-1.181)$ & 0.154 \\
\hline Other & 166 & & $2.769(1.325-5.786)$ & 0.007 & 311 & & $1.425(1.072-1.894)$ & 0.015 \\
\hline \multicolumn{9}{|l|}{ Admission group } \\
\hline Elect & 503 & $<0.001$ & Reference & & 305 & $<0.001$ & Reference & \\
\hline Emergency & 1,168 & & $2.830(1.833-4.368)$ & $<0.001$ & 2,860 & & $3.73(2.378-5.854)$ & $<0.001$ \\
\hline \multicolumn{9}{|l|}{ Cancer status } \\
\hline Local & 1,375 & 0.029 & Reference & 0.013 & 2,514 & $<0.001$ & Reference & \\
\hline Coagulation & 53 & 0.025 & Reference & & 170 & $<0.001$ & Reference & \\
\hline Liver disorder & 122 & & $0.412(0.172-1.087)$ & 0.061 & 219 & & $0.867(0.593-1.266)$ & 0.460 \\
\hline Mental disorder & 275 & & $0.680(0.325-1.427)$ & 0.308 & 256 & & $0.974(0.679-1.399)$ & 0.888 \\
\hline Renal disorder & 156 & & $0.619(0.278-1.379)$ & 0.240 & 541 & & $0.855(0.613-1.193)$ & 0.357 \\
\hline Respiratory & 276 & & $0.494(0.233-1.045)$ & 0.065 & 379 & & $0.916(0.646-1.300)$ & 0.624 \\
\hline Cardiovascular & 691 & & $0.626(0.300-1.307)$ & 0.212 & 1,443 & & $0.728(0.521-1.017)$ & 0.063 \\
\hline Other & 98 & & $0.665(0.223-1.988)$ & 0.466 & 157 & & $0.910(0.504-1.644)$ & 0.755 \\
\hline \multicolumn{9}{|l|}{ SOFA } \\
\hline$<3$ & 728 & $<0.001$ & Reference & 0.534 & 1,132 & $<0.001$ & Reference & $<0.001$ \\
\hline$\geq 3$ & 943 & & $1.136(0.760-1.697)$ & & 2,033 & & $1.448(1.181-1.776)$ & \\
\hline
\end{tabular}

Table 3 (continued) 
Table 3 (continued)

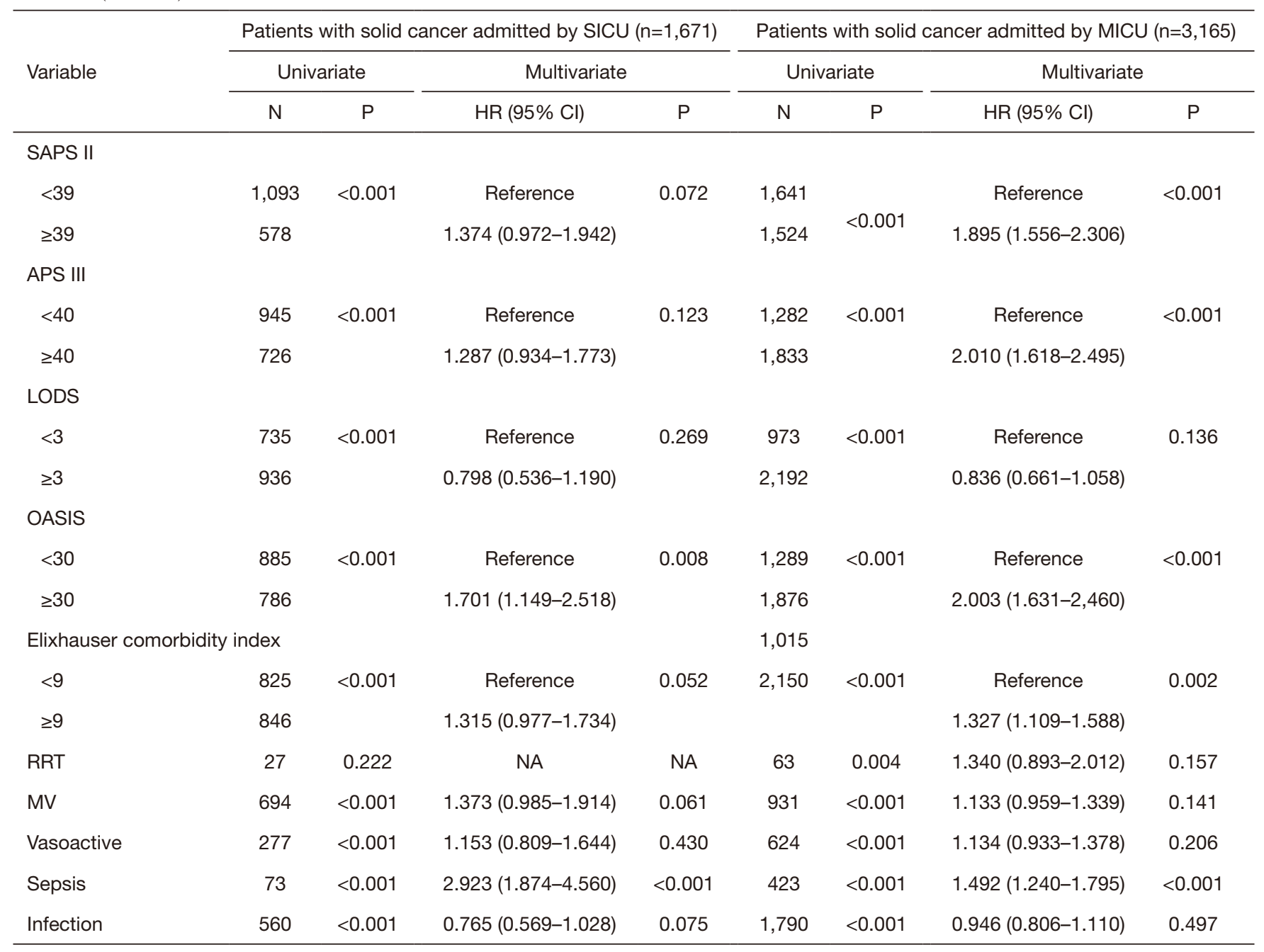

SICU, surgical intensive care unit; MICU, medical intensive care unit; N, number; P, probability; HR, hazard ratio; CI, confidence interval; NA, not application; SOFA, Sequential Organ Failure Assessment; SAPS II, Simplified Acute Physiology Score II; APS III, Acute Physiology Score III; LODS, Logistic Organ Dysfunction Score; OASIS, Oxford Acute Severity of Illness Score; RRT, renal replacement therapy; MV, mechanical ventilation.

28-day survival. Patients with solid tumors once occurred sepsis in SICU, as opposed to those without sepsis, had increased risk of 28-day mortality of 1.923 -fold. The similar increased risk of 28-day mortality in MICU was 0.492 -fold.

Many severity of illness scores have been developed and used to predict the prognosis of critically ill patients in general ICUs. Few of the severity of illness scores were used to predict outcome for critically ill cancer patients though they included some cancer-related indicators. Schellongowski et al. (26) compared three scoring systems and found that there is no advantage of a specific oncological scoring system over the general scores. Groeger et al. (27) demonstrated that goodness-of-fit, evaluated by calibration curves and the Hosmer-Lemeshow method, and area under the ROC curve were better for the ICU cancer mortality model than for the general score. In this study, the severity of illness scores of cancer patients in MICU were relatively high, compared with those of cancer patients in SICU. For patients with solid tumors in SICU or MICU, OASIS score and SAPS II had more advantages than other score in predicting ICU mortality.

Our study also had shortcomings. First of all, this was a retrospective study in a single center, despite the large sample size. Secondly, the inability to obtain the 
Table 4 Discriminatory power of five severity of illness scores in predicting ICU survival in patients with solid cancer in SICU and MICU

\begin{tabular}{|c|c|c|c|c|c|c|c|c|}
\hline Scores & \multicolumn{4}{|c|}{ SICU } & \multicolumn{4}{|c|}{ MICU } \\
\hline APS III & 52 & $52.89 \%$ & $84.52 \%$ & $0.726(0.704-0.748)$ & 51 & $74.94 \%$ & $73.15 \%$ & $0.811(0.796-0.824)$ \\
\hline OASIS & 33 & $78.51 \%$ & $71.13 \%$ & $0.824(0.805-0.842)$ & 37 & $70.62 \%$ & $80.26 \%$ & $0.819(0.806-0.833)$ \\
\hline SAPS II & 43 & $61.98 \%$ & $80.97 \%$ & $0.791(0.770-0.880)$ & 46 & $71.07 \%$ & $79.20 \%$ & $0.820(0.806-0.833)$ \\
\hline SOFA & 5 & $47.11 \%$ & $82.00 \%$ & $0.685(0.663-0.708)$ & 5 & $66.51 \%$ & $77.84 \%$ & $0.790(0.775-0.804)$ \\
\hline
\end{tabular}

ICU, intensive care unit; SICU, surgical intensive care unit; MICU, medical intensive care unit; AUC, area under curve; CI, confidence interval; APS III, Acute Physiology Score III; OASIS, Oxford Acute Severity of IIIness Score; SAPS II, Simplified Acute Physiology Score II; LODS, Logistic Organ Dysfunction Score; SOFA, Sequential Organ Failure Assessment.

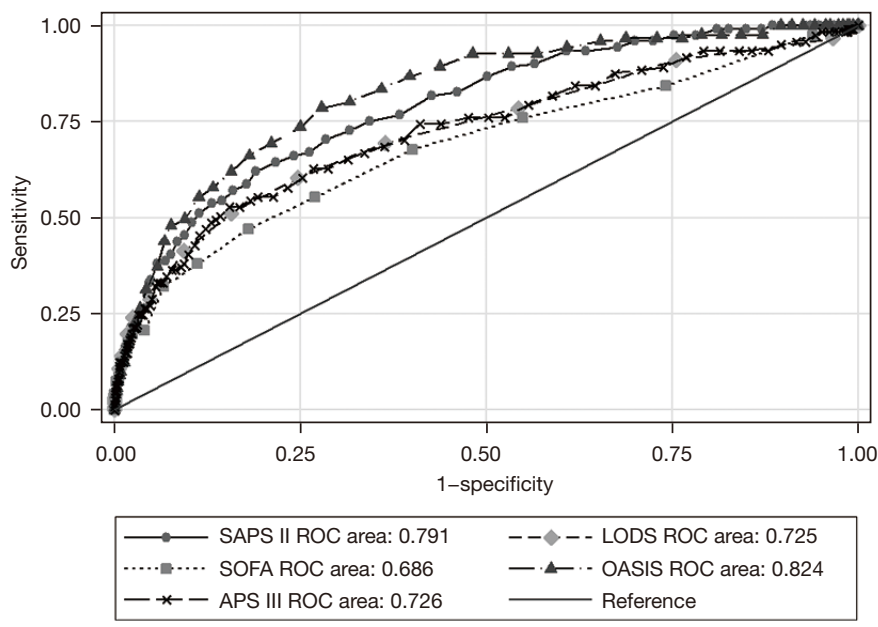

Figure 2 Five severity of illness scores in predicting ICU survival in patients with solid cancer in SICU. SAPS II, Simplified Acute Physiology Score II; ROC, receiver operating characteristic; LODS, Logistic Organ Dysfunction Score; SOFA, Sequential Organ Failure Assessment; OASIS, Oxford Acute Severity of Illness Score; APS III, Acute Physiology Score III; ICU, intensive care unit; SICU, surgical intensive care unit.

cancer stage, it may be a factor affecting patients' shortterm survival. Thirdly, the diagnosis time of malignancy is unclear, which may be more than 2 years earlier than the time they were admitted to the ICU. Those who survive with tumor-free for 5 years can be considered as completely cured. Lastly, in order to protect the privacy of patients, the time when patients enter the ICU in the database is shifted to an uncertain time in the future. And the time for each patient is different. We regret that it was unable to do the research to assess whether there has been a change related to patients' prognosis in recent years compared to the earlier.

\section{Conclusions}

A great increase in the number of patients need critical care due to improvements in oncology. In the overall population, cancer patients in SICU have short- and medium-term survival advantages. We recommend expanding the criteria of admission to the ICU for cancer patients. They should also be allowed to conduct ICU trials with unlimited ICU support. 


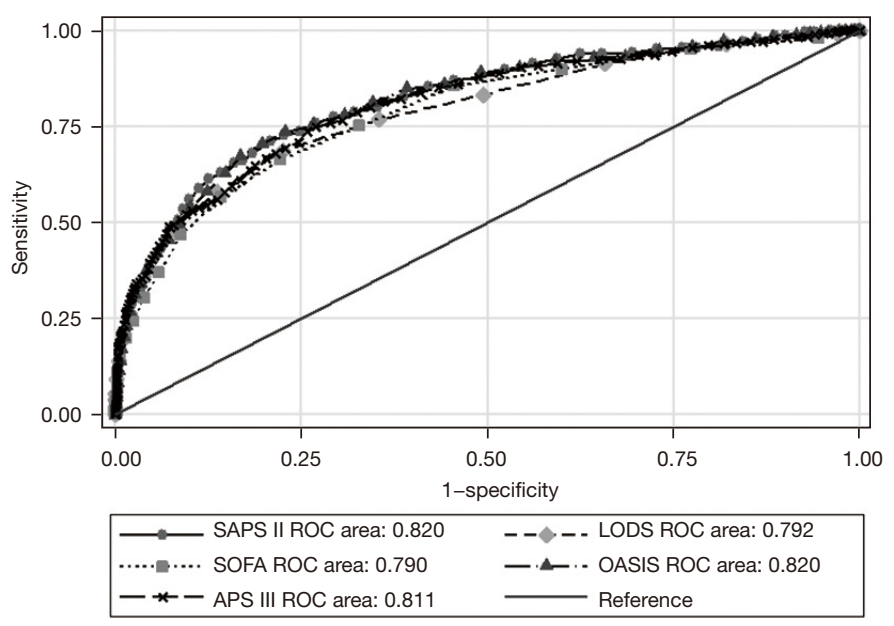

Figure 3 Five severity of illness scores in predicting ICU survival in patients with solid cancer in MICU. SAPS II, Simplified Acute Physiology Score II; ROC, receiver operating characteristic; LODS, Logistic Organ Dysfunction Score; SOFA, Sequential Organ Failure Assessment; OASIS, Oxford Acute Severity of Illness Score; APS III, Acute Physiology Score III; ICU, intensive care unit; MICU, medical intensive care unit.

\section{Acknowledgments}

Funding: None.

\section{Footnote}

Reporting Checklist: The authors have completed the STROBE reporting checklist. Available at https://apm. amegroups.com/article/view/10.21037/apm-21-2352/rc

Peer Review File: Available at https://apm.amegroups.com/ article/view/10.21037/apm-21-2352/prf

Conflicts of Interest: All authors have completed the ICMJE uniform disclosure form (available at https://apm. amegroups.com/article/view/10.21037/apm-21-2352/coif). The authors have no conflicts of interest to declare.

Ethical Statement: The authors are accountable for all aspects of the work in ensuring that questions related to the accuracy or integrity of any part of the work are appropriately investigated and resolved. The study was conducted in accordance with the Declaration of Helsinki (as revised in 2013).

Open Access Statement: This is an Open Access article distributed in accordance with the Creative Commons Attribution-NonCommercial-NoDerivs 4.0 International
License (CC BY-NC-ND 4.0), which permits the noncommercial replication and distribution of the article with the strict proviso that no changes or edits are made and the original work is properly cited (including links to both the formal publication through the relevant DOI and the license). See: https://creativecommons.org/licenses/by-nc-nd/4.0/.

\section{References}

1. Darmon M, Azoulay E. Critical care management of cancer patients: cause for optimism and need for objectivity. Curr Opin Oncol 2009;21:318-26.

2. Price KJ, Thall PF, Kish SK, et al. Prognostic indicators for blood and marrow transplant patients admitted to an intensive care unit. Am J Respir Crit Care Med 1998;158:876-84.

3. Mattiuzzi C, Lippi G. Current Cancer Epidemiology. J Epidemiol Glob Health 2019;9:217-22.

4. Siegel RL, Miller KD, Fuchs HE, et al. Cancer Statistics, 2021. CA Cancer J Clin 2021;71:7-33.

5. Puxty K, McLoone P, Quasim T, et al. Risk of Critical Illness Among Patients With Solid Cancers: A PopulationBased Observational Study. JAMA Oncol 2015;1:1078-85.

6. Hawari FI, Nazer LH, Addassi A, et al. Predictors of ICU Admission in Patients With Cancer and the Related Characteristics and Outcomes: A 5-Year Registry-Based Study. Crit Care Med 2016;44:548-53.

7. Olaechea Astigarraga PM, Álvarez Lerma F, Beato 
Zambrano C, et al. Epidemiology and prognosis of patients with a history of cancer admitted to intensive care. A multicenter observational study. Med Intensiva (Engl Ed) 2021;45:332-46.

8. Bos MM, Verburg IW, Dumaij I, et al. Intensive care admission of cancer patients: a comparative analysis. Cancer Med 2015;4:966-76.

9. Martos-Benítez FD, Soler-Morejón CD, Lara-Ponce $\mathrm{KX}$, et al. Critically ill patients with cancer: A clinical perspective. World J Clin Oncol 2020;11:809-35.

10. Taccone FS, Artigas AA, Sprung CL, et al. Characteristics and outcomes of cancer patients in European ICUs. Crit Care 2009;13:R15.

11. Griffiths J, Fortune G, Barber V, et al. The prevalence of post traumatic stress disorder in survivors of ICU treatment: a systematic review. Intensive Care Med 2007;33:1506-18.

12. Johnson AE, Stone DJ, Celi LA, et al. The MIMIC Code Repository: enabling reproducibility in critical care research. J Am Med Inform Assoc 2018;25:32-9.

13. Angus DC, Linde-Zwirble WT, Lidicker J, et al. Epidemiology of severe sepsis in the United States: analysis of incidence, outcome, and associated costs of care. Crit Care Med 2001;29:1303-10.

14. Vincent JL, de Mendonça A, Cantraine F, et al. Use of the SOFA score to assess the incidence of organ dysfunction/ failure in intensive care units: results of a multicenter, prospective study. Working group on "sepsis-related problems" of the European Society of Intensive Care Medicine. Crit Care Med 1998;26:1793-800.

15. Le Gall JR, Lemeshow S, Saulnier F. A new Simplified Acute Physiology Score (SAPS II) based on a European/North American multicenter study. JAMA 1993;270:2957-63.

16. Le Gall JR, Klar J, Lemeshow S, et al. The Logistic Organ Dysfunction system. A new way to assess organ dysfunction in the intensive care unit. ICU Scoring Group. JAMA 1996;276:802-10.

17. Johnson AE, Kramer AA, Clifford GD. A new severity of illness scale using a subset of Acute Physiology

Cite this article as: Yuan ZN, Wang HJ, Gao Y, Qu SN, Huang CL, Wang H, Zhang H, Xing XZ. Short- and mediumterm survival of critically ill patients with solid cancer admitted to the intensive care unit. Ann Palliat Med 2022;11(5):1649-1659. doi: 10.21037/apm-21-2352
And Chronic Health Evaluation data elements shows comparable predictive accuracy. Crit Care Med 2013;41:1711-8.

18. Pollack MM, Patel KM, Ruttimann UE. The Pediatric Risk of Mortality III-Acute Physiology Score (PRISM III-APS): a method of assessing physiologic instability for pediatric intensive care unit patients. J Pediatr 1997;131:575-81.

19. van Walraven C, Austin PC, Jennings A, et al. A modification of the Elixhauser comorbidity measures into a point system for hospital death using administrative data. Med Care 2009;47:626-33.

20. Rosa RG, Tonietto TF, Duso BA, et al. Mortality of Adult Critically Ill Subjects With Cancer. Respir Care 2017;62:615-22.

21. Soares M, Caruso P, Silva E, et al. Characteristics and outcomes of patients with cancer requiring admission to intensive care units: a prospective multicenter study. Crit Care Med 2010;38:9-15.

22. Temel JS, Greer JA, Muzikansky A, et al. Early palliative care for patients with metastatic non-small-cell lung cancer. N Engl J Med 2010;363:733-42.

23. Mokdad AA, Singal AG, Yopp AC. Advances in Local and Systemic Therapies for Hepatocellular Cancer. Curr Oncol Rep 2016;18:9.

24. Berghmans T, Crokaert F, Markiewicz E, et al. Epidemiology of infections in the adult medical intensive care unit of a cancer hospital. Support Care Cancer 1997;5:234-40.

25. Danai PA, Moss M, Mannino DM, et al. The epidemiology of sepsis in patients with malignancy. Chest 2006;129:1432-40.

26. Schellongowski P, Benesch M, Lang T, et al. Comparison of three severity scores for critically ill cancer patients. Intensive Care Med 2004;30:430-6.

27. Groeger JS, Lemeshow S, Price K, et al. Multicenter outcome study of cancer patients admitted to the intensive care unit: a probability of mortality model. J Clin Oncol 1998;16:761-70. 